New Zealand journal of industrial relations, 1983, 8, 147-160

\title{
A new concept of the production of industrial accidents: a sociological approach
}

\author{
Tom Dwyer*
}

Various commentators have expressed dissatisfaction at the predominant methods of analysing and preventing accidents. An ethnographic study, little used as a method for investigating industrial accident production, was carried out on a French construction site. This produced new insights into how accidents are produced. Working within an actionalist perspective a theoretical model of industrial accident production is built. This model is derived from the sociology of work, its workings are illustrated by reference to our field study and some of the literature. This model ruptures with the dominant means of analysing accident causation and of conceiving accident prevention. The article tentatively suggests that the social relations of work may become a central and profitable focus of future attempts to analyse and prevent industrial accidents.

\section{Introduction}

There is a dominant feeling amongst reviewers of industrial safety programmes and research that current methods of analysing and seeking to reduce industrial accidents are meeting with little success. (National Institute of Industrial Psychology, 1972; Ellis, 1975; Jones, 1973) This has lead to a generalised sentiment that "radically new theories are needed in accident research" (National Institute of Industrial Psychology, 1972). A later overview survey broke with tradition when it concluded that:

for maximum effectiveness, safety programmes should concentrate on those practices that can successfully deal with "people" variables (Cohen, 1977, p.177).

It did not, however, attempt to theorise the nature or importance of such variables.

A number of commentators have indicated that a major gap in industrial accident research methods exists; the lack of close empirical studies of the workplace. It has been suggested that this gap is leading to a poor understanding of the causes of accidents. (Faverge, 1967) Le Plat (1978, pp. 338-9) states:

the relevance of the accident analysis depends upon the relevance of the work analysis on which it is based. Any analysis of an accident is supported - in most cases implicitly - by a model of work on which it is based.

He goes on to make a plea:

it is ... necessary to become better acquainted with the worker, the technical installation, the workplace, the organisation and their manners of functioning, in

* Tom Dwyer is a Wellington based free-lance sociologist. He is currently the post-doctural fellow in the Department of Sociology at the University of Canterbury (to where all communication should be addressed). The fieldwork in this study was carried out whilst he was a post-graduate student in France. The assistance and insight of Alain Touraine is gratefully acknowledged, as is the support of the CFDT's construction sector committee for Paris and the Paris OPPBTB. The author would like to thank the journal's 2 anonymous referees for their comments. 
short, of all the different systems in which the worker is situated in order to usefully define the conditions under which accidents occur. It is to this extent that the study of accidents can be related to the general study of work conditions.

From the above 2 sets of observations it could be speculated that: the lack of adequate theoretical conceptualisations of the causes of industrial accidents, the lack of close and systematic analyses of the workplace and the generally observed ineffectiveness of dominant accident prevention techniques, are interlinked. Should this be so, a close empirical workplace study could produce new theoretical insights into the production of accidents and eventually lead to the formulation of more effective prevention techniques. But an extensive literature search showed such a study represented a new approach, even within the tradition of the sociology of work. Nichols (1975, p. 217) summarised the "state of the art" as:

A strange situation this ... that in the overwhelming number of cases, injury and ill-health should not figure in the works of industrial sociologists.

However Nichols $(1975$, pp. 221-1) goes on to emphasise the social character of the production of industrial injury, and in so doing provides further confirmation that our speculations are worthwhile pursuing:

injuries at work occur in the context of the social relations of production .... injuries and fatalities take place in a particular mode of production which is characterised by particular social relations; one moreover in which sociologically, if not existentially, neither managers nor men are free agents.

\section{The choice of research methods and sites}

Based on the above speculations, and operating within a sociological tradition, we decided to carry out a series of field studies in a dangerous industry. A dangerous industry was chosen for it was here, we thought, that worker consciousness about accident production would be the most clearly developed. We had already worked in and conducted research (Dwyer, 1980) into the construction industry; given our technical expertise, it appeared appropriate to conduct further research in this high accident industry. The decision was made to carry our research of an ethnographic nature on 6 French construction sites.

In this article an account of 1 of the sites researched will be presented. We have chosen to present this particular site for two reasons: (a) a purely pragmatic one; it is a small site hence its dynamics are explicable within the space constraints of the article; (b) it portrays types of work relations rarely discussed in modern organisational literature. Field techniques of semi-structured interviewing, observation or work and the analysis of written documents were employed (these are explained and justified in more depth in Dwyer 1981, pp. $4-6 ; 1978$, pp. 140-9). Triangulation was used to check the validity of data gathered by 1 method against that gathered by another (Denzin, 1970).

\section{One construction site : an ethnographic study}

Looking at this site from down below it appears very thin. Very grey also. It is going to be a service tower for an office complex hence it has been designed with no coloured panels, and no windows. A single crane protrudes from its centre. It will be 15 storeys when completed, it is not a large site, $400 \mathrm{~m}^{2}$ per floor. Four gangs work on the site, each is composed of 4 men. In addition, a general foreman and a site foreman are employed to supervise the work.

As one approaches the site, the lack of exterior scaffolding permits a clear view of some workers. A person wearing a red helmet, dressed in blue overalls, opening and closing a skip as he pours a concrete wall can be observed ... his manoeuvering is sometimes compli- 
cated, he has 1 foot on each side of the boxing as concrete runs into the space between his feet. Pointing sharply towards him are naked rods of stressing steel. He is working 5 floors above ground level without any guard rail to prevent his falling off the boxing. The skip is sometimes difficult to open .... sometimes easy .... the concrete appears to run too quickly on occasions, and not at all on others. Because no one knows how quickly the concrete is going to pour, he runs the risk of losing his balance (should it pour forth in a manner for which he is not prepared) and falling into thin air. "Fortunately" I think to myself "there's no wind".

I skirt around the outside of the site to another side. Here there's a guard rail in place at the top of the boxed wall. A safety platform is in place 3 metres below the 3 men to be seen there. They work on a small platform next to the boxing and stressing rods of "their wall" ... the yellow skip now moves to their side ... the guard rail is taken off to allow it to approach .... the crane's jib is but 3 metres above their heads ... a guard rail would interfere with the performance of their task ... they too have problems with the skip but fortunately their small platform gives them a greater working surface than their previously observed workmate had. Should they fall and "fall well" they would land on the protective platform placed only 3 metres below them, should they "fall badly" they would land 6 storeys down. The 3 workers and the skip occupy nearly all of the available space on the platform.

These first observations completed, I enter the site for the first time, accompanied by the parent company's safety engineer. We are greeted by the site's general foreman and proceed to climb artificially lit staircase after staircase. Traces of dust indicate that the steps have been recently swept. As we climb, the safety engineer says to the general foreman "It's not good at all", in referring to what he and I had observed. We arrive on the work decks, the corridors are blocked, there is rubbish everywhere . . . he replies "If we haven't any guard rails, it's because we haven't had time to install them . . we work quickly here ..."

We meet the site foreman ... after having heard some unfavourable comments from the safety engineer he turns to me. "Are the sites like this in your country?" The field worker's pretensions of "neutrality" are instantly rendered hollow by such a question. "No", I reply, running the risk of becoming his enemy. "You don't work over there" he bellows

you spend all your time on safety .... we work quickly here ....we've gotta move ... the building has to be finished next week, we had 3 months to do it 15 floors in 3 months (the botton 8 floors are below ground level) ... there's a plan here that we must follow, if not we'll have no more contract - we're working for the next contract ... over there (indicating towards the site)

His leathery face twists as he continues:

we're obliged to scream here to make the guys work ... it's like that we make them work ... for 6 years I've worked like that, I'm obliged to ... Safety, you know to put a safety plank there (he indicates the place), it should be there, but it's necessary to go down 2 storeys to find a plank ... we won't go and look for it, it'd make us work more slowly.

Whilst speaking, he looked at his men ... sometimes yelling at them ... we were 3 or 4 bunched in the centre of the floor, a group of 4 men behind us were working in an elevated position preparing boxing. Two workers on one side of the building were preparing more boxing, they were working a metre above us on a platform at the exterior of the building. In front of us the worker with a red helmet was still standing on his boxing, some 3 metres above the floor. Next to him, 2 workers on a platform appear to be doing very little, there being no more concrete to pour. On our right, high above us, the 3 men who were pouring concrete as we arrived were finishing their work and putting back their protective railing. This gang (the 3 men plus the red helmeted worker), it was explained to me, was the "lead-gang" on the site. Each gang works more or less individually, and no communication can be seen between gangs.

Once left alone on the site I was free to observe and talk at length with the men. Supply delays had produced (what was acknowledged as) a rare "calm period" for life on this site. 
On the basis of preliminary interviews the response to the question "How do you like your job?" produced different replies that indicated a key dimension for understanding the functioning of this particular site. The responses given to this question were dependant on neither the ethnic background nor the level of qualification of the workers. Workers responses saw them divided into 2 distinct groups: those dissatisfied with their job and those satisfied with it. Strong antagonism was shown by the dissatisfied workers towards their satisfied counterparts. The dynamics of this tension, its origins within the systems of management employed on the site, and the relationship of these systems to the production of industrial accidents, were clarified through further interviewing. Two of the "dissatisfied" explained their feeling towards the "satisfied" ...

There are 3 or 4 guys here who are good with the bosses; when the bosses say "we'll give you a raise ${ }^{1}$ if you work like this" they listen to them. When it was snowing we were the only site in the area that kept working ... because that prick there (they point to the man wearing the red helmet) said he'd work, and we were obliged to follow, otherwise it would have been the street.

The foreman had apparently offered him a bonus to induce him to work.

That guy (he's nicknamed "the motor") takes risks that others won't take ... he's for the bosses ${ }^{2}$ he's had accidents because of that, but he'd do anything for a bit more money.

This worker in the red helmet confided:

Sure safety, it's important ... yeah, I've had accidents, recently something fell on my nose, you see (indicating the bump on his nose) ... but it's like that in the construction industry.

He accepted the danger and felt he had a priviliged position on the site. When I asked him about the dangerous manner in which he'd been seen pouring concrete he replied with a drooped jaw, shrugged shoulders and a refusal to speak. Taking up a point 1 of his "satisfied" workmates (A member of the gang I'd seen pouring concrete. This was the "lead gang" and had the role of setting the work pace for the site.) related "There's nothing missing here for safety." I indicated the badly placed planks visible on some work platforms, the holes in the floor, missing safety rails, workplace disorganisation and work pressures ... "That's okay, a fall could happen to anyone ... there'll always be accidents."

These workers, the "satisfied", were detested by the others; they consented to the danger of their task. In order to maintain this consent, they were paid the highest salaries of all workers. To maintain this privileged position, they were offered and accepted, incentives which were paid when they took risks that the others would be reluctant to take. For them, there did not seem to be any "problem of safety" since their own interests in gaining material rewards were directly linked to a lack of safety by the financial incentives offered by management. Their accidents occurred because they took risks in order to earn incentives. For the employers this translated into a double benefit, safety measures could be economised on, and, a split was obtained amongst the workers. This split was able to be manipulated so as to increase the relative pace of production of the site. The example cited of work proceeding in the snow provides 1 example of this.

The "dissatisfied", who were in different gangs to the "satisfied", showed that they were subject to a different system of management. One crucial difference was that these workers did not receive any incentive payments for the work they performed. Before examining this group in depth, let us take a closer look at how work on the site is organised.

Work appeared, from available indications, to be carried out expeditiously. The lack of complicated construction techniques (in comparison with other sites examined) presents itself as a striking feature. This feature reduces the relative levels of skill required for effective task execution. The gangs are organised so as to work independently of one

1 Officially payment by results no longer exists in this company - having been abolished as a result of union action on other sites. On this non-unionised site the "payments" are offered "under the table" in the form of raised salaries.

2 The general foreman said that this same worker was " a bosses man." 
another. This building is constructed in spiral fashion, the "lead gang" works at the highest level and, as it moves from one task to another, it keeps climbing, the other gangs finish off the jobs started by the gang which precedes them in accordance with their formally defined task. The fact that work proceeds in a spiral means that gangs never work "on top of others" (a dangerous yet common arrangement in the construction industry). The site is small, the workers can normally maintain visual contact with each other. The number of sub-contractors is very limited. Potential sources of accidents emanating from the underqualification of the workforce, or the disorganisation of the workplace have been largely eliminated due to the planned manner in which the site has been organised.

Beyond these observations of the site, lie the general feelings of the "dissatisfied workers", these indicate a reality invisible to the naked eye. For 2 dissatisfied workers who clearly articulate a shared perception:

the problems here come from the foremen, they push us all the time ... work, work - for them all that counts is concrete ... if we ask for safety they don't give a stuff .... who's going to die here? Not they!

Why do these 2 immigrant workers agree to work in such circumstances?

We can't refuse to work in these conditions. We're fathers and we need money, not unemployment .... we came (to France) looking for work, not for a fight ... and look at what we've got!

The impotence felt by these workers, and the divisions on the site due to the fact that some workers are "good with the bosses" appear to have an effect on the whole lives of the "dissatisfied". "I can't have sex with my wife because of this bloody job ... I sleep downstairs, she upstairs".

The site foreman explained in an interview that 1 worker had cut his finger off because he was working too quickly. He did not explain why work was routinely performed at unsafe speeds except by referring to external time constraints on the job and individual carelessness. The "dissatisfied" workers engaged in another level of explanation, they interpreted their work speed, their accidents and near misses as being due to the authoritarian control of the site.

This type of control was able to be maintained due to the workers incapacity to defend themselves collectively: as individuals they feel unable to leave this job because of the high unemployment rate in the industry. "I've had several accidents here, because of the speed (pushed by the foreman), all have been small ... but 1, I fell and only just saved my life". Or as it was said at a more general level "There are lots of accidents because the boss pushes ... that's the problem".

The functioning of this site is dominated by a mixture of authoritarianism (for the "dissatisfied") and incentive payments (for the "satisfied"). For the foremen this is justified: "We've got to go quickly here". They don't deny that the required speed leads to accidents, but remain unconcerned about them; after all they themselves never have any.

The accidents occurring to the "dissatisfied" workers and the dangers to which they are exposed appear, on analysis, to be produced, above all, by the authoritarianism used to manage the site and via which they are "made to work". The "satisfied" workers treat danger as a part of their task for which they receive higher salaries and incentive payments. They do not appear to be subject to authoritarian control. Their acceptance of financial incentives, in return for the taking of risks, appears overwhelmingly, as the most important producer of their exposure to danger and hence of their accidents.

\section{Conclusion of the field study}

The foreman, at 1 stage during the research, wanted to show me the good side of his site. He led me to the guard rails that existed, the holes that had been covered over, the protected and well-lit stairway. It is true that a certain number of safety measures were in place. One must however ask to what extent they would have existed if independent 
workplace inspection did not exist? The foreman was able to determine in advance when my research was going to take place, and according to 1 worker: "They've organised some protection today, they didn't do it for me, they did it for the inspections. When you've gone, it'll be just like it was yesterday." I reflected on the staircase that appeared to have been recently swept . . . "I built this guard-rail," 1 man said proudly. "When?" I asked. "This morning, first thing."

In spite of the lack of technical complexity, from an engineering point of view, this research lead me to hypothesise that the social relations existing on the site would be such as to produce a high accident rate. The site statistics showed that during the 3 month construction period there had been 5 lost time accidents, these resulted in 155 lost days for a total of 17285 hours worked (including foremen). This frequency rate was more than 4 times the national average for the sector ( 28.9 accidents per 100000 hours worked), the severity rate was 14.75 days (approximately 120 hours) lost for every 1000 hours worked $^{3}$.

\section{Towards a sociological understanding of the production of industrial accidents}

Our ethnographic study has suggested that a range of factors within the workplace can be seen as being responsible for the production of industrial accidents. What appears to be interesting is that the key factors identified as producing accidents, authoritarianism and financial incentive systems, are virtually ignored in the dominant literature written for and used in the study of safety mangement (e.g. Heinrich, 1950: Malasky, 1974). For some writers the theoretical groundings of this literature has more to do with promoting the mobility of certain professions (e.g. Noble, 1977, p. 289 ff.) For others, the grounding is based on little more than attempts to deform science in order to blame worker carelessness for the majority of accidents (See Faverge, 1967, pp. 55-2). In both cases, the theories developed appear to have little to do with the reduction of industrial accidents. Attempts to test hypotheses drawn from these theories are carried out, in the main, in such a manner as to deny the relevance of social (as opposed to individual) factors in the operation of the workplace and the production of accidents. That literature which seeks to analyse the workplace, and to see industrial accidents as located therein, appears to deal with selected aspects of the problem. Typically, it examines either 1 type of accident (Friedmann, 1964: Turner, 1967), or, when based on workplace studies, neglects to examine relationships between observational and interview material and accident record and rate data (e.g. Fitzpatrick, 1980: Di Naro, n.d: Pilcher, 1972). In addition, it is unfortunate that the vast majority of field studies carried out within the sociology of work seem to ignore the systematic treatment of issues arising out of safety and accidents in the workplace.

A sociological understanding of the production of industrial accidents must perceive of high or low rates in such a way that they are linked neither to the "nature" of an industry, nor of the individuals working therein, nor of the materials it transforms and the work processes employed. It must attempt to ask questions such as the following:

What social processes operate that result in a rise in accident rates in 1 industry (firm, plant etc) whilst they fall in another? and then ask: If the social processes identified as contributing to a low accident rate in 1 industry (firm, plant etc.) were to be introduced where accident rates were high, could not an overall reduction in the industry's (firm's, plant's, etc.) rate be achieved?

A sociological model of the production of industrial accidents must, through its very formulation, attempt to locate the answers to the above questions within the transformation of the social relations of work. In attempting to lay out such a theoretical model, we must go beyond the narrow confines of the data presented in the French field study, and into an examination of other relations of work treated in the literature.

3 It is not possible to calculate the differential rates for the "satisfied" and "dissatisfied" workers due to the organisation of accident records and man hour statistics on the site. 


\section{Building the model}

An industrial accident involves the sudden cessation of work and consequent human injury. ${ }^{4}$ Industrial accidents are produced in the workplace; it is here that people, as a function of their intellectual and physical capacities, act. They act on machines, materials, ideas, nature, etc. in order to transform them.

Social anthropology has taught us that the decision to work or to not work on a substance, a tool, etc, can only be made socially because all work is made up of physical and intellectual elements which cannot be separated from their social context. The idea that a person works on nature or at machines that are socially neutral, that are independent of any social relations, is false. A person only works on transformed social relations. The application of knowledge and of manual ability to nature, tools, etc cannot start without their being seized and conceived socially thus these "things" are "social relations transformed into things". At any point in time and space they, and the manner in which they are conceived and seized, are the product of what Touraine (1980) has called "society's action upon itself". These "things" are worked upon by those who act within a system of historical action. We will call them transformed social relations (TSRs).

\section{Four levels of reality}

Four analytically separate levels of reality can be distinguished in industrial work. Each of these levels is differentiated from the others by its functioning. The levels are ...

(1) Rewards

(2) Command

(3) Organisation

(4) Individual-Member

The first 3 levels are socially constructed. The fourth level is made up of that autonomy for action that has been left to the individual-member within the context of the social relations of work. The explicit function of social relations at each level of social reality is, at the limit, to benefit the dominant party.

From the point of view of the dominant party in an industrial capitalist firm ${ }^{5}$ the rewards level refers to the reproduction of the productive forces (labour and capital) for a cost below the price received for the product of these forces. The command level refers to the dominant party's taking active control of the actions of the dominated party. The organisational level refers to the dominant party's taking charge of the knowledge and coordination of the TSRs on which the dominated party works.

An industrial capitalist firm cannot continue to exist if it finds itself thwarted with respect to the rewards function. This function does not however, necessarily dominate the day-to-day work lives of employees. One of the other 2 functions may exert dominance on

4 Unlike many other observers we do not conceive of, for methodological reasons relating to difficulties of operationalisation, non-injury accidents as a focus of analysis. On a theoretical level these are the product of the same work relations as injury accidents, but the relationship between injury and noninjury accidents is not a simple arithmetic one. (c.f. Shannon, 1980) By referring to the "sudden cessation of work" we have excluded industrial illness from consideration.

5 A characteristic of an industrial capitalist firm is that an important part of the surplus gained from the productive process is invested, once again, in the productive process in order to transform working conditions and, in the classical model, the division of labour. All such firms are the product of the accumulation of capital. (Touraine, 1973, p. 121) We have chosen to treat the industrial capitalist firm as the unit of analysis since it is the dominant form of organisation within which accidents occur in the advanced western nations such as we have examined in our fieldwork. The theory to be developed is in no way undermined by our pointing out that some of the social relations to be discussed were formed in preindustrial societies, and that anecdotal or written accounts from the communist bloc countries produce explanations of accident causation consistent with those developed herein. 
them, and through this dominance the firm realises its objectives at the rewards level. Our model will attempt to show the possible effects of the functioning of social relations in the workplace, and since it is to be applied to the study of industrial accidents it will be oriented around an analysis of manual work. The dominant party in the workplace will be called the employers (and their agents in the workplace will be called management,) the dominated party will be called the workers.

\section{The composition of the social levels of reality}

The organisational level, when pushed to the extremes of its development, forms a social relation in which workers carry out their manual work without any questioning of their relationship with the TSRs. The employers organise and co-ordinate relations between workers and their TSRs. They monopolise the distribution of knowledge as to the state of the TSRs.

Conflict occurs at this level when workers and employers contest the distribution of knowledge about the co-ordination of the TSRs.

Modern management literature speaks extensively of the organisation of productive processes and of task co-ordination. The basic assumption contained in this literature is that management, as the employer's agents, are responsible for controlling the knowledge about and the co-ordination of machines, tools, stock, etc. (e.g. Barnard, 1938: Taylor, 1971). Taylor sees "Taylorism" explicitly as a technique to strip workers of the knowledge and right to question their relationships with their TSRs and to transfer this knowledge to management. For Braverman "The more science is incorporated into the labour process, the less the worker understands of the process". (1974, p. 425)

The general consequences of the development of Taylorism such as the increased fragmentation of tasks and the routinisation of work are now well documented, and represent a key feature of the contemporary workplace in industrial capitalist societies.

Workers are, through the development of the organisational level by employers, gradually transformed into the mere executants of an unskilled manual task; employers, through their domination at this level gradually control all the knowledge and co-ordination of the TSRs and, on the basis of this control, manage the workplace to their own benefit. The workers end up working either at a monotonous task, at a task for which they do not have adequate knowledge of their relationship with those TSRs external to that task (disorganisation), or they lack the necessary knowledge and skill to successfully transform the TSRs upon which they work (underqualification). In any work situation where the organisational level is dominant, any 1 or all of these factors may affect the worker. The degree to which these effects are realised depends on the nature and extent of domination at this level.

When pushed to the extremes of its development the command level forms a social relation in which employers have the power to direct workers' actions to such an extent that they act on parts of the work system in a manner that they consciously recognise as being against their own interest.

When this level exercises dominance in the day-to-day functioning of the workplace, the employers benefit due to the workers being unable to oppose the tasks imposed upon them. The breaking of workgroup cohesion ensures continued employer domination of workers.

Conflict occurs at this level when the workers organise themselves collectively to contest their employer's power and when the employers seek to break worker power and workgroup organisation.

Texts detailing aspects of the history of Great Britain's industrialisation provide accessible in-depth discussion on the functioning of this level. ${ }^{6}$ Modern organisational literature

6 See Tressell (1967) for a novelistic account, Thompson and Yeo (1971) for a journalist's impressions and Building Accident Committee (1907) and Children's Employment Commission (1842) for some close insights into worker, employer and various professional conceptions of the operation of the
command level. 
appears to speak little of the control of workplaces in these terms. Fox sees recourse to the employment of power as a last resource available to management "when their authority falters, breaks down or cannot come effectively into existence" (1972, p. 47)

Through the development of this level to its limits workers are ultimately reduced to a group without knowledge of their workmates - employers become authoritarian. In this manner the employers control the execution of work at the command level.

When pushed to the extremes of its possible development, the rewards level forms a social relation in which workers can only earn enough money by working long or unusual hours. Employers, through linking the amount of money a worker earns to his/her productivity, run the workplace profitably.

Employers may implement profit sharing, production bonuses or danger money payments in order to link the amount of work done to the wages paid and eventually to the profit generated. The practicalities of various types of financial incentive schemes are discussed in management literature (e.g. Fayol, 1971, p. 27 ff.). Workers thwarted in their attempt to reproduce or produce their own desired conditions of material existence through working a "reasonable" number of hours, resort to working unreasonably long or unusual hours. ${ }^{7}$ Most western trade unions, by supporting the concept of "a living wage in return for a 40 hour working week", oppose the working of overly long hours. Conflict occurs at this level when, to give 2 examples, workers attempt to achieve their financial goals by thwarting the operation of incentive schemes, or when managers contest the number of hours being worked, considering that such work is affecting the firm's capacity to make a profit.

The reward level links the firm, as a seller of goods and services produced, to the market place. Workers are linked to the market place as individuals who buy, with the fruits of their labour, goods and services for consumption. Domination by the rewards level in the workplace ensures that employers make a profit through obtaining workers' participation in financial incentive schemes. Workers can be reduced to a situation where, to satisfy their material needs independently of such schemes, they resort to working unreasonably long hours.

\section{The composition of the individual-member level}

There exists another level of reality in the workplace. A level which is not analysable as a functioning relation of social domination, its role is however, to a large extent limited (but never determined) by the functioning of the social relations of work. This level represents what is left to the individual worker, that part of him/her which has not been organised, commanded or rewarded. We call this "remainder" the individual-member level.

The worker expresses himself individually, arriving at work in a happy state perhaps because he has just become a father or by arriving at work intoxicated. The worker can act individually at 1 of the social levels in order to reinforce the employer's or the worker's power at that level. The individual sabotaging an assembly line, the undercover organiser of a trade union and the rate-buster in a piecework factory all express different dimensions of this level of reality. The saboteur refuses the assembly line as the controller of his/ her work speed. The organiser seeks to collectively contest the command power of his/her employers. The rate-buster seeks self enrichment through accepting the employer's definitions of work and refusing the counter-definition made by fellow workers.

When linked to a social level of reality, action engaged in at the individual-member level can profoundly shape the future functioning of that level. The social articulation of such action is necessary to ensure its success in changing the relations of dominance within a level. Management literature discusses limiting and controlling the negative effects of the individual-member level on the smooth running of the company. Bureaucratic rules (Goul-

7 In the case of an industrial worker this can range from the Brazilian worker who seeks a bare subsistance wage, to a North Sea oil platform diver who seeks a salary that will allow him to own 2 cars and a boat. 
dner, 1954), "discipline" and social psychology are tools employed in an effort to reward, command and organise this level, to subject the autonomy remaining to the worker to the logic of social domination. Employers sometimes seek to harness this level of reality in order to break collective worker control at a given level of social reality; the encouragement of the rate-buster in order to break rate-fixing is just one example. During the recruitment or job-transfer process employers (sometimes with union backing) may seek to "screen out" employees with "individual-member characteristics" considered to be undesirable for a particular job (e.g. colour blindness, slow auto-motor reactions, sensitivity to heat), and in so doing reduce accidents produced by the interaction between certain individual characteristics and the design of certain tasks. The task remains unchanged, but the people are changed.

\section{Power relations}

The relative importance of each level in the production of goods and services undertaken in the workplace is determined socially. Factors internal and external to the workplace limit these determinations. Power relations are not "hidden behind" the mode of functioning of each level, the social relations existing at each level are the result of and the expression of power relations as they form and reform in the workplace through repression, consensus and struggle.

The dominance of any 1 level is an expression of both conflict within the workplace and the influence of those external factors (e.g. at an abstract level, economy, law, culture, and in the concrete example of our French site, the threat of inspections) that limit the social formation of the workplace. The dominance of 1 level, as opposed to another, is nothing other than the expression of power relations. A change in the relative dominance of a level within the workplace is an expression of a change in power relations.

In applying the model of industrial accidents to the analysis of work, it must be remembered that the categories that have been developed in this article are idealisations. It is rare to find a workplace where 1 level of social relations exercises total dominance, equally it is rare to find a particular social relation operating in a pure form "pushed to the extremes of its development".

Analytically different patterns of social relations may, at different moments and for different workgroups, exist within the same workplace. We can thus conceive of 2 workgroups working at the same process within a factory -1 lacks training while the other, a well trained group, is highly motivated by the offer of piece-rate payments. Their accident rates are similar. A union or a mangement decision to suspend piece-rate payments could, according to the model developed, be expected to result (other things remaining equal) in the lowering of the accident rate for the latter group, whilst not affecting the rate of the former.

\section{Putting the model to work}

How do the categorisations developed in the model assist us to conceptualise the causation and prevention of industrial accidents? What empirical evidence does the literature provide to validate our choice of analytical categories? Before seeking to answer this question we must note that sociological perspectives appear to have had little influence on the overall focus of research or on action taken in the name of industrial accident prevention. The evidence presented in the rest of this article will be derived from those few studies that can be interpreted as having operationalised the various social relations which make up our theoretical model. ${ }^{8}$

8 To the best of our knowledge this sociological model of industrial accidents (and its more sopisticated variant found in Dwyer (1978)) is the only theoretical model currently available that permits the various empirical results cited here to be treated as integral parts of the same holistic conception. 
At the rewards level 2 ideal types of social relation were defined. In the first, incentive systems dominated work lives, in the second, workers' lives were entirely dominated by the long or unusual hours worked. Friedmann says that, the (bonus) worker finds himself in a situation where he must work fast in order to have a high salary. Thus he is led not to use those safety devices which depend on him (such as safety glasses, masks, gloves, etc) because they often prevent him from obtaining a rise in salary. (1964, p. 112)

A lowering of the dominance of this particular social relation appear to have been brought about by a 1969 strike in a Swedish ore mine which resulted in the abolition of incentive payment programmes. This abolition was followed by a 95 percent fall in severe accidents between 1969 and 1972: less severe accidents fell by 70 percent. The same study reported that minor accidents rose by some 32 percent. This latter rise was interpreted as being due to the workers feeling freer to seek medical attention, formerly some would have continued working in spite of such injuries in order to maintain their levels of bonus payment. (Hazards Bulletin,1977 p. 7) On the French site, we discovered the existence of a social relation involving the employment of financial incentives, and it was this relation that was adjudged to dominate the work lives, the production of dangerous work and accidents of the "satisfied" workers.

The working of excessive hours was co-related with high accident rates by Friedmann who noted that a drop in working hours from 12 to 10 per day in a munitions factory was followed by a 25 percent decline in the accident rate $(1964$, p. 115). On the French site, excessive hours were not worked, a government decree had, as one tool in the fight against unemployment, outlawed overtime work in the construction industry.

At the command level we can see the dominated contesting its own felt domination through use of its collective force. A weakening of this collective force can lead to a rise in employer authoritarianism. This has important ramifications for the production of industrial accidents because it can produce work in dangerous situations, work which would have previously been refused. Turner (1967) discusses a situation in which a rise in accident rates occurred in a factory after union delegates had been dismissed. Hill and Trist's study (1955, p. 50) emphasised the consequences of a decrease in employer command pressure. They explained a drop in accident rates between day and night shift operations as being due to the lower level of supervisory authority operating on nightshift.

In our French site we saw that employer authoritarianism was a key method of achieving high production from the "dissatisfied workers". They perceived of it as the major cause of their accidents. It would be consistent with the specifications of the model to hypothesise that any lessening of this authoritarianism would, other things remaining equal, lead to a reduction in their accidents.

The lack of ability of workers to effectively communicate amongst themselves is identified as an idealised social relation at the command level. Faverge (1967, p. 49) discusses a German study of 3 factories which showed that 10 percent of accidents were attributable to the fact that a communication was inexact or poorly understood. A study carried out in Paris showed that 5.1 percent of fatal construction accidents were due to "a lack of co-ordination between workers performing the same task" (Wisniewski, 1977, p. 108). On the French site examined, no clear evidence was presented to point to the existence of this social relation. In the absence of finer grained measuring instruments (perhaps derived from sociometry), we can hypothesise that any attempt to reduce accidents by increasing the degree of effective communication on this site would be unsuccessful.

At the organisational level workers may lack the knowledge necessary to carry out their jobs in safety because management has not provided them with such knowledge. This expresses itself in the underqualification of workers or in the disorganisation of the workplace. In both cases, workers have accidents because they lack knowledge of those TSRs with which they enter into relation.

In order to counter the effects of underqualification, workers may demand and/or employers may provide training programmes. In spite of the extensive literature on such programmes (cf. Milutinovich and Phatak (1978) for one example) little clear evidence is provided as to the reductions appropriate training programmes can produce. On the 
French site examined, there was no evidence as to the existence of this relation, nor to the existence of disorganisation. This absence appeared, from the fieldwork, to be to a large extent due to the way in which the site had been planned by management.

Disorganisation is discussed as a cause of accidents in much of the mainstream accident prevention literature. Prevention of disorganisation is seen in the concept of "good housekeeping". At a more critical level, Dassa (1976, pp. 406-7) examines and critiques the role played by the designers of work in producing workplace disorganisation and its dangers. Once again, a lack of close empirical studies frustrates our ability to find evidence confirming that a rise or fall in disorganisation is co-related with a rise or fall in accident rates.

The worker can, at the organisational level, be transformed into the mere executant of a manual task for which he/she has the necessary knowledge. This task, however, lacks variety and is of a repetitive nature. The continued performance of such a task can lead to fatigue, boredom or over-familiarity. Industrial accidents are seen to be a consequence (Caillard, 1976, p. 281). This phenomenon was not found on the French site examined. In an effort to reduce the effects of this work, ergonomically designed tools and machines may be introduced by management (or as a response to union or state pressure). The work of Wisner (1972) in France has, with trade union support, been influential in bringing ergonomic perspectives to bear in the redesign of repetitive work.

At the individual-member level workers act out that liberty which has not been suppressed or controlled for in the workplace. This can generate accidents when the worker knowingly or unknowingly places himself or workmates in danger as a result of such action. In addition, the individual-member may have certain innate characteristics that are undetected by management's screening practices. In certain cases these characteristics may lead to accidents. A colour blind worker can, for example, cause specific accidents that colour sighted workers would not cause.

A great deal of thinking about industrial accidents has been oriented around diagnoses of individual human characteristics or actions. These are seen as the principal causes of accidents. The prevention methods suggested by such analyses imply that increasing various types of managerial control of the individual-member is the only efficient course to follow. Employers and managers are thus freed from having to consider the role played by the șocial relations of work in producing industrial accidents.

On the French site examined, no evidence was produced to demonstrate that the individual-member level was responsible for the production of accidents. It was certainly possible that a "dissatisfied" worker could act at this level in an attempt to discipline the "satisfied" workers. Such action could easily involve the latter being deliberately exposed to considerable danger by a member of the former group.

It is doubtful whether the individual-member level, isolated from the other levels in the workplace (and outside of its "screening for the job" aspect), plays an important role in producing real industrial accidents. Empirical tests of relevant hypotheses, such as accident proneness, have never established their general validity. (Faverge, 1967, p. 156: Crawford, 1974: Cronin, 1971, p. 131).

\section{Conclusion}

The sociological model of industrial accidents developed in this paper produces a new, theoretically grounded, attempt to firstly conceptualise and secondly categorise the social relations which produce accidents. In so doing, new methods of analysis and the consequent strategies of prevention are opened up for systematic application.

Having conceptualised the causes of accidents in this manner and, in so doing, having made their prevention dependent on changes in social relations, we have departed radically from the politics of dominant perspectives on accident prevention. In so doing, we have hoped to add a new axis to the attempt to find methods by which accident rates can be lowered. This paper represents little more than a small attempt to expose what may one day provide a basis for the "radically new theories . . . needed in accident research". 
Should it do so, the focus of attention in accident prevention will be shifted away from attempts to change the workers and the machines. The social relations of work will become the focus of analysis and change.

\section{References}

Building Accidents Committee (1907) Report of the Departmental Committee Appointed to Enquire into the Dangers Attendant on Building Operations London, HMSO.

Barnard, C. (1938) The functions of the executive Cambridge, Harvard University Press.

Braverman, H. (1974) Labour and monopoly capital New York, Monthly Review Press.

Caillard, J.F. (1976) A propos du facteur humain des accidents du travail: Attitudes et securite Cahiers des comites de prevention du batiment et travaux publics $6: 280-282$.

Children's Employment Commission (1842) First Report of Commissioners London, HMSO.

Cohen, A. (1979) Factors in successful occupational safety programmes Journal of safety research 9(4) : 168-177.

Crawford, W. (1973) Accident proneness - an unaffordable philosophy Australian safety news 44 (4) : 11-15.

Cronin, J.B. (1971) Cause and effect? Investigations into aspects of industrial accidents in the United Kingdom International labour review 103 (2) : 99-115.

Dassa, S. (1976) Travail salarie et sante des travailleurs Sociologie du travail 18 (4):394-410.

Denzin, N. (1970) The research act Chicago, Aldine.

Di Naro, C., et al. (n.d.) Securezza e produttivita: influenza delle variabili tecologiche sul comportamento lavorativo Securitas 58 : 743-755.

Dwyer, T. (1978) Une conception sociologique des accidents du travail Doctoral thesis, Paris, $\mathrm{L}$ ecole hes hautes etudes en sciences sociales.

Dwyer, T. (1980) Hit and miss Industrial relations review 1 (6) : 24-30.

Dwyer, T. (1981) Industrial accidents and night work in the manufacturing sector Wellington, New Zealand Department of Labour.

Ellis, J. (1975) A review of research on efforts to promote occupational safety in Journal of safety research 7 (4) : 180-189.

Faverge, J.M. (1967) Psychosociologie des accidents du travail Paris, PUF.

Fayol, H. (1971) General principles of management In D.S. Pugh (Ed) Organisation theory London, Penguin.

Fitzpatrick, J. (1980) Adapting to danger Sociology of work and occupations 7(2):131-158.

Fox, A. (1972) A sociology of work in industry London, Collier-MacMillan.

Friedmann, G. (1964) Industrial society New York, The Free Press.

Gouldner, A. (1954) Patterns of industrial bureaucracy New York, The Free Press.

Hazards bulletin (1977) October.

Heinrich, H.W. (1950) Industrial accident prevention New York, McGraw-Hill.

Hill, J. and Trist, E. (1955) Changes in accidents and other absences with length of service Human relations $8: 121-153$.

Jones, D.F. (1973) Occupational safety programmes are they worth it? Toronto, Ontario Ministry of Labour.

Le Plat, J. (1978) Accident analysis and work analysis Journal of occupational accidents $1: 331-340$ 
Malasky, S.W. (1974) System safety New Jersey, Hayden.

Milutinovich, J.S. and Phatak, A.V. (1978) Carrying the safety training load - tips for all managers Industrial engineering 10 (November): 24-32.

Nichols, T. (1975) The sociology of accidents and the social production of industrial injury. In G. Esland et al.(Eds) People and work Edinburgh, Holmes McDougal.

National Institute of Industrial Psychology (1972) A review of the industrial accident research literature London, HMSO.

Noble, D.F. (1977) America by design New York, Knopf.

Pilcher, W.W. (1972) The Portland longshoremen New York, Holt, Rinehart and Winston.

Shannon, H.S. (1980) Differences between lost-time and non-lost time industrial accidents Journal of occupational accidents $2: 265-272$.

Taylor, F.W. (1971) Scientific management In D.S. Pugh (Ed) Organisation theory London, Penguin.

Thompson, E.P. and Yeo, E. (1971) The unknown Mayhew London, Penguin.

Touraine, A. (1973) La production de la societe Paris, Seuil.

Touraine, A. (1980) The self-production of society University of Chicago Press.

Tressell, R. (1967) The ragged trousered philanthropists London, Grenada.

Turner, J.A. et al.(1967) Labour relations in the motor industry London, Allen and Unwin.

Wisner, A. (1972) Consequences du travail repetitif sous cadence sur la sante des travailleurs et les accidents Paris, Laboratoire de Physiologie du Travail, CNAM.

Wisniewski, (1977) Accidents mortels sur les chantiers du baitment et des travaux publics dans la region Parisienne Cahiers des comites de prevention du batiment et travaux publics 2 : 101-108. 